\title{
Government health insurance for people below poverty line in India: quasi-experimental evaluation of insurance and health outcomes
}

\author{
Neeraj Sood associate professor ${ }^{123}$, Eran Bendavid assistant professor ${ }^{45}$, Arnab Mukherji associate \\ professor $^{6}$, Zachary Wagner PhD student ${ }^{7}$, Somil Nagpal senior health specialist ${ }^{8}$, Patrick Mullen \\ senior health specialist ${ }^{8}$
}

\begin{abstract}
Department of Pharmaceutical Economics and Policy, School of Pharmacy, University of Southern California, Los Angeles, CA, USA; ${ }^{2}$ Leonard D Schaeffer Center for Health Policy and Economics, University of Southern California, Los Angeles, CA, USA; ${ }^{3}$ National Bureau of Economic Research, Cambridge, MA, USA; ${ }^{4}$ Division of General Medical Disciplines, Stanford University, Stanford, CA, USA; ${ }^{5}$ Center for Health Policy and the Center for Primary Care and Outcomes Research, Stanford University, Stanford, CA, USA; ${ }^{6}$ Center for Public Policy, Indian Institute of Management Bangalore, Bangalore, India; ${ }^{7}$ School of Public Health, UC Berkeley, Berkeley, CA, USA; ${ }^{8}$ World Bank, New Delhi, India
\end{abstract}

\begin{abstract}
Objectives To evaluate the effects of a government insurance program covering tertiary care for people below the poverty line in Karnataka, India, on out-of-pocket expenditures, hospital use, and mortality.

Design Geographic regression discontinuity study.

Setting 572 villages in Karnataka, India.

Participants 31476 households (22 796 below poverty line and 8680 above poverty line) in 300 villages where the scheme was implemented and 28633 households (21 767 below poverty line and 6866 above poverty line) in 272 neighboring matched villages ineligible for the scheme.

Intervention A government insurance program (Vajpayee Arogyashree scheme) that provided free tertiary care to households below the poverty line in about half of villages in Karnataka from February 2010 to August 2012.

Main outcome measure Out-of-pocket expenditures, hospital use, and mortality.

Results Among households below the poverty line, the mortality rate from conditions potentially responsive to services covered by the scheme (mostly cardiac conditions and cancer) was $0.32 \%$ in households eligible for the scheme compared with $0.90 \%$ among ineligible households just south of the eligibility border (difference of 0.58 percentage points, $95 \%$ confidence interval 0.40 to $0.75 ; \mathrm{P}<0.001$ ). We found no difference in mortality rates for households above the poverty line (households above the poverty line were not eligible for the scheme), with a mortality rate
\end{abstract}

from conditions covered by the scheme of $0.56 \%$ in eligible villages compared with $0.55 \%$ in ineligible villages (difference of 0.01 percentage points, -0.03 to $0.03 ; P=0.95$ ). Eligible households had significantly reduced out-of-pocket health expenditures for admissions to hospitals with tertiary care facilities likely to be covered by the scheme $(64 \%$ reduction, $35 \%$ to $97 \%$; $P<0.001)$. There was no significant increase in use of covered services, although the point estimate of a $44.2 \%$ increase approached significance ( $-5.1 \%$ to $90.5 \%$; $P=0.059)$. Both reductions in out-of-pocket expenditures and potential increases in use might have contributed to the observed reductions in mortality.

Conclusions Insuring poor households for efficacious but costly and underused health services significantly improves population health in India.

\section{Introduction}

Tertiary care is often too expensive for people with low incomes. As a result, those with conditions requiring tertiary care often go untreated or are left with devastating hospital bills, both of which exacerbate poverty. ${ }^{1}$ In addition, the burden of ischemic heart disease and cancer-diseases that can potentially be dealt with in tertiary care-is rising in many countries with a lot of poverty such as China, Bangladesh, and India. ${ }^{23}$ To meet the need for tertiary care while providing financial security to people with low incomes, several states in India have rolled out social insurance programs that provide free tertiary care to households below the poverty line. These insurance programs are financed 
through tax and typically do not require premiums or user fees from beneficiaries. ${ }^{45}$ The Vajpayee Arogyashree scheme (VAS) was launched for this purpose in February 2010 in Karnataka, India, a state with over 60 million residents and nominal gross domestic product per capita of about $\$ 1400(£ 834, € 1048)$ in 2011. ${ }^{6}$ (Vajpayee is the name of a former Indian prime minister, and Arogyashree means "disease-free.") The scheme entitled eligible participants to free care for a targeted range of tertiary care services, mostly cardiac, oncologic, neurologic, burn, and trauma care. Like other insurance schemes, it aims to improve use of services for unmet healthcare needs while reducing often catastrophic out-of-pocket expenditures associated with complex illnesses. ${ }^{7}$ Unlike India's national health insurance program for people in poverty at the time of our study (Rashtriya Swasthya Bima Yojna), however, the Vajpayee Arogyashree scheme covers only tertiary care and requires no enrollment or annual premiums. It also incentivizes providers to seek patients with cardiac and oncologic conditions whose treatment requires costly specialized care. We evaluated the extent to which this scheme led to changes in health outcomes and utilization among its intended beneficiaries.

There is limited evidence on the impact of health insurance on the health and economic wellbeing of beneficiaries in developing countries. ${ }^{8}$ Published reviews suggest that while insurance improves utilization and reduces personal expenditures, the evidence on health outcomes is mixed. ${ }^{8-11}$ Evidence from Colombia suggests that the rapid expansion of health insurance in the 1990s led to an improvement in neonatal health outcomes. ${ }^{12}$ Studies in Thailand and the United States also provide evidence for possible health benefits when the insurance scheme is well matched to the health burden and target population. ${ }^{13}{ }^{14}$ On the other hand, several studies have found a heterogeneous or null effect of insurance on health outcomes. An evaluation of a randomized roll out of Mexico's Seguro Popular, which offers extensive insurance coverage for people below the poverty line, found it decreased catastrophic health expenditures but had a mixed effect on utilization and health improvements. ${ }^{15-19}$ Similarly, evaluations of insurance and user fee reduction schemes in Burkina Faso and Ghana found reductions in catastrophic health expenditures without improvements in health outcomes..$^{20-22}$ A study of the expansion of national health insurance in Costa Rica in the 1970s found little impact on long term trends in child mortality. ${ }^{23}$ More recent evaluations of China's health system reforms, including the rural New Cooperative Medical Scheme and the Urban Resident Basic Medical Insurance, show significant heterogeneity in the estimated impact on health outcomes and costs, although at least some subpopulations probably experienced increases in utilization and financial protection. ${ }^{24} 25$

We evaluated outcomes of the scheme, recognizing that its unique coverage features-a discrete bundle of services that were selected for their established efficaciousness, close match with high burden epidemiological targets, and underuse - provided a potentially compelling approach for promoting health improvements with insurance. We exploited the phased roll out of the scheme to measure its impact on utilization, financial protection, and mortality. Initially, it offered insurance to residents below the poverty line in two administrative divisions comprising several districts in the northern part of the state of Karnataka; in August of 2012 the scheme decided to extend insurance coverage to households below the poverty line in the entire state. During this staggered implementation, we evaluated the program's outcomes using a quasi-experimental design that took advantage of the sharp boundary in coverage. In particular, we compared outcomes in neighboring villages on either side of the boundary drawn between the communities chosen for early versus late implementation

\section{Methods \\ The Vajpayee Arogyashree insurance scheme}

Most beneficiaries of the scheme were poor and lived in rural areas with little or no access to tertiary care. Residents in eligible areas who possessed a "below poverty line" card issued by the state government were automatically enrolled. This enabled beneficiaries to receive free tertiary care at both private and public hospitals empanelled by the scheme as capable of providing tertiary care. Beneficiaries paid no premiums or co-payments at the point of service. As of June 2013, the scheme empanelled about 150 hospitals capable of providing tertiary care, including all major medical centers in the state. Hospitals received a fixed bundled payment based on a reimbursement schedule for more than 400 tertiary care service packages in cardiology, oncology, neurology, nephrology, neonatology, burn care, and trauma care (see appendix table A4). As most hospitals are in urban centers in southern Karnataka while beneficiaries are located in villages as far as several hundred kilometers away, empanelled hospitals were required to organize health camps in rural areas to screen patients for tertiary care and transport eligible patients to hospitals. Hospitals signed an agreement to conduct these health camps during the empanelment process and received a fixed payment per health camp conducted. Most rural patients receiving care through the scheme were identified through these health camps.

\section{Experimental design}

We exploited the phased roll out of the Vajpayee Arogyashree scheme to measure its impact on utilization, financial protection, and mortality. In February 2010, it offered insurance to residents in the northern part of the state of Karnataka; in August 2012 insurance coverage was extended to the entire state. During this staggered implementation, we evaluated the program's outcomes using a quasi-experimental design that took advantage of the arbitrary boundary in coverage. In particular, we conducted surveys in September 2012 and compared outcomes in neighboring villages on either side of the boundary drawn between the communities chosen for early versus late implementation. Although surveys were conducted after coverage had been announced for the southern part of the state, implementation in southern districts was slow and spillover was minimal. Of the 4000 admissions to hospital that were covered by the scheme in our six study districts before we conducted the surveys, only 140 were from southern districts.

We did not believe that the close geographical proximity within one Indian state of the early (which we term "treatment") and late ("control") implementation villages would have an effect on outcomes of interest other than through access to the scheme. We were thus able to use the geographic discontinuity to look at outcomes in eligible areas compared with outcomes in adjoining ineligible areas without introducing selection bias. To reinforce similarity between eligible and ineligible households, we selected treatment and control villages to study by matching on geographic proximity, demographics, and socioeconomic characteristics. In particular, we used the last available census data (2001) to randomly select 300 control villages using probability proportional to size (population) in the three ineligible districts just south of the eligibility border (in Shimoga, Davangere, and Chitradurga districts) and matched these villages (with replacement) to 272 similar treatment 
villages in the three districts just north of the eligibility border (Uttara Kannada, Haveri, and Bellary). We sampled 24 villages twice and one village five times. Figure $1 \Downarrow$ shows the geographical proximity of the sampled villages. The villages were matched by identifying the "nearest neighbor" based on propensity scores. The census variables used to estimate propensity scores included the proportion of the population aged over 6 , sex composition of population aged under 6 , the proportions of schedule caste and schedule tribe (historically disadvantaged communities), female literacy rate, and population employed. Table $1 \Downarrow$ shows that treatment and control villages were balanced on all characteristics included in the propensity score models.

Because we collected data only after implementation, the above experimental design will produce an unbiased estimate of the effect of the scheme on health outcomes only if households in matched eligible and ineligible areas were similar on all important observed and unobserved determinants of outcome measures. We tested this assumption by comparing differences in outcomes across the eligibility border for households above the poverty line. We expected no difference in outcomes for these households as they were ineligible for the scheme irrespective of location.

\section{Study population}

Figure 2 shows our study population $\Downarrow$. In September 2012, we enumerated all households in the selected villages (44 571 households in the eligible villages and 38186 households in the ineligible villages). Respondents were asked for the primary reason for any admission to hospital during the past year from a list of 33 broad conditions; we then conducted an additional survey in all households with an admission for a potentially covered condition and a random sample of households with admissions for conditions not covered (910 households out of 10324 with admissions for condition not covered).

\section{Data sources}

\section{Enumeration survey}

All households in sampled villages were asked to participate in a door to door survey, and $81 \%$ of them completed the survey. Surveyors recorded information on whether the household had a state issued below poverty line card, anyone in the household was admitted to hospital in the past year, and any members of the household died in the past year. All questions were administered in Kannada, the local language. After excluding 22648 households that claimed below poverty line status but could not produce the card, we analyzed information on 31476 households in eligible villages ( 22796 below poverty line and 8680 above poverty line) and 28633 households in ineligible villages ( 21767 below poverty line and 6866 above poverty line) (fig $2 \Downarrow$ ).

Households with a death or admission to hospital in the past year were asked to identify the cause of death or admission from a list of 33 causes, translated into lay terms. Interviewers were able to verify self reported cause of admission with hospital records available at time of interview from about two thirds of participants. We used information on cause of death to create our primary mortality indicator, identifying all households that reported a death in the past year from a potentially covered condition (a condition for which a service covered by the scheme could have been preventive or curative). We also recorded the age at death and sex.

We used the information on admissions to measure utilization rates. We created two measures to estimate use of potentially covered services by individuals below the poverty line. First, we estimated utilization as all admissions for potentially covered conditions in any tertiary care facility. Second, to better discriminate between admissions in tertiary care facilities where a covered service was actually received and admissions where a covered service was not received (for example, an admission for observation to rule out a myocardial infarction), we created a measure of utilization that excluded admissions to the emergency department only and admissions with a length of stay of four days or less. The rationale is that most services covered by the scheme include planned procedures and lengthy admissions. The scheme's administrative data show more than three quarters of covered stays lasted longer than four days. The count data for both measures was denominated by the total number of households surveyed.

In addition to use of tertiary care, we also measured differences in forgone need for tertiary care. This measure was based on a question that asked respondents if any household member forwent care for a serious illness, and, if "yes," to identify the illness for which care was forgone.

\section{Household survey}

All households below the poverty line with an admission for a potentially covered condition and about $10 \%$ of households with a condition not covered participated in a detailed household survey. We thus surveyed 487 and 479 households with potentially covered and not covered conditions, respectively, in eligible villages and 486 and 392 households with potentially covered and not covered conditions, respectively, in ineligible villages (fig $2 \Downarrow$ ).

The household survey asked respondents to detail out-of-pocket health expenditures for all admissions. Total out-of-pocket expenditures were calculated as the sum of spending on hospital charges, medicines, and diagnostic tests.

\section{Asha survey}

In addition to the enumeration and household surveys, the study team interviewed one community health worker (Asha) in each village (sample size 572). We collected village level information on demographics, socioeconomic characteristics, and health behaviors.

\section{Census and district level household surveys}

We used two existing datasets to characterize differences or similarities between eligible and ineligible areas. We used the latest available 2001 census for data on demographic indicators including proportion of population aged under 6 , proportion from historically disadvantaged communities (referred to as scheduled caste or tribe), female literacy rate, and proportion employed. We used the third round of the district level household survey conducted in our study area between December 2007 and March 2008 for data on mortality rates prior to implementation of the scheme. The survey is an ongoing survey commissioned by the government of India that surveys about 1500 households in each district. We used responses to a question that asked respondents about any deaths in the family since January 2004 to characterize baseline mortality rates in the study districts.

\section{Statistical analysis}

We first evaluated differences between eligible and ineligible villages using $t$ tests. We focused on differences in demographics, mortality, health related behaviors, and 
socioeconomic or development indicators. Demographic indicators were extracted from the 2001 census and baseline mortality indicators were extracted from the 2007-08 district level household survey. Indicators for health related behaviors were extracted from the Asha survey and included whether most men used tobacco or were heavy drinkers. Development indicators were also extracted from the Asha survey and included village availability of piped water, electricity, banks, an all weather road, government primary health centers, and private clinics.

We next used a logit model to compare differences in mortality rates in 2012 for covered conditions in households below the poverty line between eligible areas and ineligible areas. We also used multivariate logit regressions to control for demographics, health related behaviors, and development indicators described above. Standard errors were clustered at the village level. We then used the same methods to compare mortality among households above the poverty line for the same conditions in eligible and ineligible villages. We expected to find no differences in mortality for households above the poverty line as these households were not eligible for the scheme. Any differences in mortality for potentially covered conditions in households above the poverty line could reflect pre-existing differences in mortality.

The secondary outcomes for the study included out-of-pocket expenditures, utilization of tertiary care for conditions covered by the scheme, and foregone need for tertiary care. For each secondary outcome we used ordinary least squares to look at differences in means for households below the poverty line in eligible areas compared with similar households in ineligible areas. We also estimated multivariate ordinary least squares models for these secondary outcomes, clustering standard errors at the village level. The multivariate models for out-of-pocket expenditures controlled for differences in illness or health condition composition by including an indicator variable for each of the seven conditions covered by the scheme. We also estimated these models controlling for demographic characteristics, health related behaviors, and development indicators; as the sample of people admitted to hospital was rather small, addition of too many covariates could lead to over-fitting of the model and therefore our model of choice adjusted only for illness composition, which was the most important confounder. The models for utilization of tertiary care controlled for demographics, health related behaviors, and development indicators. Standard errors were clustered at the village level for all analyses because villages served as the primary units in the sample selection; we also repeated all analyses while clustering the standard errors at the district level, without a qualitative change to the significance level.

\section{Results \\ Baseline data}

We found no pre-existing differences in mortality rates (measured in 2004-08) between treatment districts (north of border and eligible for the scheme) and control (south of border and ineligible) districts (see appendix table A3). Socioeconomic and health behavior characteristics were also balanced on all but one measure (table $2 \Downarrow$ ); a bank was available in a greater proportion of control villages (35\% (94) compared with $25 \%$ (75) of treatment villages, $\mathrm{P}=0.012$ ).

\section{Study outcomes Mortality}

Mortality from conditions covered by the scheme was lower among eligible households below the poverty line but similar among households above the poverty line (fig $3 \Downarrow$ ). Among households below the poverty line, the mortality rate from conditions covered by the scheme was $0.32 \%$ in eligible households compared with $0.90 \%$ in ineligible households (difference of 0.58 percentage points, $95 \%$ confidence interval 0.40 to $0.75 ; \mathrm{P}<0.001 ; 64 \%$ risk reduction). There was no difference, however, in mortality rates across households above the poverty line in treatment and control areas. Among households above the poverty line, the mortality rate from conditions covered by the scheme was $0.56 \%$ in treatment areas compared with $0.55 \%$ in control areas (difference of 0.01 percentage points, -0.03 to 0.03 ). When we included controls for village characteristics from table 1 and table 2 , results were similar with a difference of 0.54 percentage points $(\mathrm{P}<0.001)$ in the mortality rate for conditions covered by the scheme. Results were qualitatively similar if we included families who claimed below poverty line status but did not have a card as families below the poverty line in the analysis (see appendix fig A7).

Figure $4 \Downarrow$ presents the age distribution at death from potentially covered conditions. We expected the age at death from covered conditions among beneficiaries of the scheme to be higher compared with non-beneficiaries if the scheme led to increasing population coverage of efficacious health services, which was supported by the results. For example, among people below the poverty line, $52 \%$ of deaths were in people aged $<60$ in eligible households compared with $76 \%$ in people ages $<60$ in ineligible households. The distribution of age at death was significantly different (Kolmogorov-Smirnov test $\mathrm{P}<0.001$ ).

\section{Out-of-pocket expenditures}

Table $3 \Downarrow$ compares out-of-pocket payments for covered conditions between households in treatment and control villages. When we included all types of facilities, the scheme was associated with a $34 \%$ reduction in out-of-pocket health expenditures for admission to hospital for covered conditions (95\% confidence interval $18 \%$ to $51 \%$ ). This included admissions that were less likely to be covered because we included care provided at any type of facility (individuals were charged for care of a covered condition that did not result in tertiary care-for example, seeking care for a cardiac condition that resulted in a prescription for antihypertensive drugs). The difference in out-of-pocket expenditures increased to $58 \%$ when we examine only admissions in tertiary care facilities $(95 \%$ confidence interval $31 \%$ to $84 \%$ ) and to $64 \%$ after we excluded short admissions and admissions through the emergency room (35\% to $97 \%$ ). All differences were more pronounced when we adjusted for illness composition and when we controlled for the baseline characteristics from tables 1 and 2 (available on request). Results were qualitatively similar when we restricted the analyses to admissions that could be verified with medical records (see appendix table A2).

\section{Utilization and foregone medical care}

We compared rates of hospital admissions between households in treatment and control villages (table $4 \Downarrow$ ). The admission rates in any facility for potentially covered conditions in the year before the survey were similar: $486(2.1 \%)$ in the eligible areas and $485(2.2 \%)$ in the ineligible areas (4.3\% difference, $95 \%$ confidence interval $-17.5 \%$ to $8.8 \%$; $\mathrm{P}=0.52$ ). Rates of 
admissions in tertiary care facilities (where admissions are more likely to result in covered services) show a trend towards greater utilization by eligible households: eligible households were $12.3 \%$ more likely to use tertiary care for covered conditions $(-20.3 \%$ to $44.9 \%$; $\mathrm{P}=0.46$ ) (table $4 \Downarrow)$. The greatest difference in utilization was observed in rates of non-emergency admissions for potentially covered conditions to tertiary care facilities that led to inpatient stays longer than four days (44.2\% difference, $-5.1 \%$ to $90.5 \%$; $\mathrm{P}=0.06$ ). Although this result was not significant at the $95 \%$ level, the point estimate was large and approached significance, which could suggest of a positive effect on utilization. Results were qualitatively similar when we controlled for the characteristics presented in tables 1 and 2 (last column of table 4) and when we restricted the analyses to admissions that could be verified with medical records (see appendix table A1).

In response to questions about forgone care, $52(0.2 \%)$ households in eligible villages and $76(0.4 \%)$ households in ineligible villages indicated that a household member had forgone care for a potentially covered illness (35.5\% reduction, $95 \%$ confidence interval $-73.5 \%$ to $2.5 \%$; $\mathrm{P}=0.07$ ) (table $4 \Downarrow$ ). Forgone care might be complementary to the increased admission rates, and the increase in admission rates for covered conditions was nearly identical to the decrease in forgone care between the two groups.

\section{Sensitivity analysis}

We conducted a series of sensitivity analyses to examine potential concerns and sources of bias. The first concern was the possibility that there was measurement error in illnesses reported as reasons for mortality, which could bias our estimates. We dealt with this in several ways. First, we restricted the estimated mortality rates to two common diseases people are generally familiar with — cancer and cardiac conditions-which are likely to have less measurement error. When we looked at mortality rates for these familiar conditions we found results similar to overall mortality (see appendix figures A1 and A2). Second, we estimated differences in mortality rates from conditions that were not covered (such as diarrhea, diabetes, asthma, and tuberculosis), where we would expect to find no effect. We found that eligible and ineligible households below the poverty line had similar mortality rates for these conditions (see appendix figure A3). Third, we looked the distribution of causes for hospital admissions from the scheme's administrative records compared with the distribution of self reported causes from our household survey. The distributions were similar, suggesting there was little measurement error in this self reported illness measure (see appendix figure A4). Finally, we examined information on reported cause of death from our household survey in ineligible areas compared with a verbal autopsy study conducted in India in 2001-03. The proportions of deaths from cancer, cardiac conditions, and chronic respiratory infections in people aged over 25 were similar in the verbal autopsy study and the household survey (see appendix figure A5). ${ }^{26}$

Next, we examined the concern that mortality benefits of the scheme might be overstated if people who were treated were left in an unproductive state of high morbidity. To assess this, we used a standard health status indicator to estimate health before and after admission to hospital for people who received procedures covered by the scheme. Beneficiaries of the scheme reported improvements in overall health after the admission to hospital and were relatively healthy at the time of the survey (see appendix figure A6). We found similar patterns for more specific health domains: ability to walk, self care, ability to do usual activities, pain, and anxiety/depression (results available from authors on request).

Finally, we assessed differences in out-of-pocket costs between eligible and ineligible households for conditions that were not covered by the scheme. As expected, we found that differences in costs for conditions not covered by the scheme were not significantly different between eligible and ineligible households (results available on request).

\section{Discussion}

\section{Principal findings}

Implementation of a health insurance program (Vajpayee Arogyashree scheme) in the northern districts of Karnataka in India led to important health benefits among people below the poverty line, with a reduction of $64 \%$ in mortality from conditions covered by the scheme. Measurable benefits also include substantial reductions in out-of-pocket costs among beneficiaries. Although we did not have the power to detect an increase in utilization of services and a decrease in foregone tertiary care, point estimates were large and approached significance, which suggests an increase in utilization.

\section{Results in context}

Prominent studies of health insurance for people below the poverty line in developing countries have commonly failed to measure health improvements. One reason why we found health improvements whereas others did not might be that the scheme covered tertiary services, which generate more immediate benefits, whereas the health effects of primary care interventions covered by other programs might not be observed for years. For instance, the evaluation of Mexico's Seguro Popular did not find changes on nine self assessed health indicators, despite improved financial security. Seguro Popular, however, covers a broad array of primary healthcare services, and the self assessed health measures were similarly broad. Similar outcomes have been observed in Ghana, Burkina Faso, and Costa Rica, while studies in China and Thailand suggest the possibility of health improvements after initiation of health insurance schemes. $^{14-27}$

The implementation features of the Vajpayee Arogyashree scheme can possibly help to explain its measured benefits, including mortality benefits that are rarely measurable in evaluations of other health insurance schemes. First, the requirement for empanelled hospitals to hold health outreach camps possibly alleviated the selection created by the provision of health insurance, whereby those who are best off are also the ones most likely to take advantage of its benefits. Instead, this feature potentially promoted the provision of services to individuals living in regions where tertiary care was rarely used and often foregone. In addition, the automatic enrollment of all below poverty line cardholders with no premiums, user fees, or co-payments removed an important barrier that could limit the use of health services among individuals in poor health. At the same time, it also instituted a pre-authorization process to mitigate the risk of overprovision of care. The focus on a discrete, costly, and efficacious set of medical conditions helped in identifying the target population that most benefitted from the scheme. Finally, services covered by the scheme were well matched to reflect conditions with a rising share of disease burden in India and whose management is otherwise inaccessible for people below the poverty line. These design features behind the scheme could be used by extension to other regions. 


\section{Strengths and limitations}

Our study had several methodological strengths, including the matching process of villages across the implementation boundaries. While we used propensity score matching using census data from several years before the study, we found that the villages matched well on multiple observed dimensions not used in the matching process, suggesting that the villages were matched on unobserved variables as well. We also focused on health outcomes proximal to the services covered by the scheme, as its circumscribed set of covered services enabled measurement of changes in cause specific mortality even if changes in general population health were difficult to measure. This study was, however, also limited in several ways. First, it was quasi-experimental in that the scheme was not randomly assigned to villages. This posed several methodological challenges but also presented opportunities for using rigorous approaches designed to reduce selection bias. The northern portion of Karnataka was selected for coverage because the state government thought that Karnataka's northern regions were in greater need of tertiary healthcare. The extent to which this is true is unknown, but for that reason we selected villages on the southern border of the eligibility area and matched them to villages just south of the eligibility boundary. The baseline data support our assumption that villages just north and just south of the border were similar on relevant characteristics. The finding of no difference in mortality for households above the poverty line also supports this important assumption. In future work we aim to resurvey these households to understand how expansion of the scheme to the south of the eligibility border affected outcomes.

Second, the classifications of causes of death by family members are important for the findings. If measurement error were a factor, we would expect to see similar patterns of misclassification among households above the poverty line where none were found. Moreover, as eligible households had more exposure to information about covered illnesses through health camps, we would expect greater reporting of these illnesses among eligible households as a potential cause of death, which would bias our findings. We also found no evidence of measurement error affecting results in the various sensitivity analyses we conducted. Nonetheless, measurement error could still be a source of bias.

Third, we could not directly measure who was covered by the scheme, only whether the admission to hospital or death was related to a condition for which management was potentially covered by the scheme. Because of this we probably analyzed admissions and deaths that were outside of the scope of the scheme together with the truly covered services, thus diluting our estimates of effect size. Indeed, our estimates of out-of-pocket expenditures and utilization increase with greater efforts to identify those admissions that were truly covered by the scheme. Moreover, these more restrictive measures were a closer match to the number of admissions reported in the scheme's administrative records.

Fourth, a related concern is that effects of the scheme on utilization of tertiary care are imprecisely estimated. It is, however, important to note that the scheme could affect mortality even in the absence such a utilization effect. For instance, health camps organized by the scheme and easier access to tertiary care might have increased individuals' likelihood of seeking primary healthcare for symptoms (such as chest pain) that might require tertiary care. This could result in earlier detection of disease, which could reduce mortality. Similarly, the scheme empanels hospitals that meet certain quality standards and thus beneficiaries might be receiving care in "better" hospitals. Finally, the scheme instituted a pre-authorization process that might have limited inappropriate use of tertiary care.

Fifth, the evidence we found of reduced mortality associated with conditions covered by the scheme could reflect a previously unmet demand for tertiary care, suggesting that the long term effect of the program might be less dramatic.

Finally, people who needed tertiary care and lived in ineligible areas might have migrated north of the eligibility border to gain access to the scheme. As such people were likely to have been sicker, it would cause us to understate the effect of the scheme on reducing mortality. Discussion with local experts and government officials, however, suggests that migration is not a big concern as it would require a new below poverty line card or address change on an existing card, both of which involve arduous and drawn out processes, especially for rural households below the poverty line.

\section{Conclusions and policy implications}

People below poverty line in India with conditions requiring tertiary care have the choice of trying to access lower cost government tertiary care services, taking on devastating debt to pay for care from private sector hospitals, or experiencing the health consequences of foregoing treatment for their illness. India is currently pursuing several strategies to improve health services for its population, including investing in government provided services as well as purchasing services from public and private providers through schemes similar to the Vajpayee Arogyashree scheme. ${ }^{48}$ While a scheme such as this might provide significant health and economic benefits to people below the poverty line, future research will need to assess the cost effectiveness provided compared with alternative social protection and health promotion programs.

We presented preliminary findings from this research to World Bank, Government of Karnataka, and academic healthcare researchers.

Contributors: NS led all aspects of the study. EB and ZW co-led all analysis and preparation of the manuscript. AM co-led data collection and helped with data analysis. SN and PM helped conceive the study, coordinated with the government, obtained research funding, and provided critical comments on research design and results. NS is guarantor.

Funding: This project was funded by the Health Results Innovation Trust Fund at the World Bank. The funding agency played no role in the conduct of this research and the decision to submit this manuscript for publication.

Competing interests: All authors have completed the ICMJE uniform disclosure form at www.icmje.org/coi_disclosure.pdf and declare: no support from any organization for the submitted work; no financial relationships with any organizations that might have an interest in the submitted work in the previous three years; no other relationships or activities that could appear to have influenced the submitted work.

Ethics approval: The study was reviewed and approved by the institutional ethics committee at Indian Institute of Management, Bangalore, India (IRB\# IORG0004307).

Data sharing: Technical appendix, statistical code, and data used in this study are available from the corresponding author.

Transparency declaration: The authors affirm that the manuscript is an honest, accurate, and transparent account of the study was reported and no important aspects of the study have been omitted.

Whitehead M, Dahlgren G, Evans T. Equity and health sector reforms: can low-income countries escape the medical poverty trap? Lancet 2001;358:833-6. 


\section{What is already known on this topic}

Health insurance schemes in developing countries can reduce financial hardship and increase utilization of healthcare Evidence on the impact on health of health insurance for people below the poverty line is mixed

\section{What this study adds}

Insuring poor households for efficacious but costly and underutilized health services, coupled with recruitment of patients who could benefit from these health services, significantly improved population health in India

2 Yusuf S, Reddy S, Ônpuu S, Anand S. Global burden of cardiovascular diseases. Part II: Variations in cardiovascular disease by specific ethnic groups and geographic regions and prevention strategies. Circulation 2001;104:2855-64.

3 Ferlay J, Shin H-R, Bray F, Forman D, Mathers C, Parkin DM. Estimates of worldwide burden of cancer in 2008: GLOBOCAN 2008. Int J Cancer 2010;127:2893-917.

4 World Bank. Government-sponsored health insurance in India: are you covered? http:// documents.worldbank.org/curated/en/2012/08/16653451/government-sponsored-healthinsurance-india-covered.

5 Fan VY, Karan A, Mahal A. State health insurance and out-of-pocket health expenditures in Andhra Pradesh, India. Int J Health Care Finance Econ 2012;12:189-215.

6 List of Indian states by GDP. http://en.wikipedia.org/wiki/List_of_Indian_states_by_GDP. Vajapayee Arogyasri home page. http://stg2.kar.nic.in/healthnew/SAST/Home.html.

Escobar M-L, Griffin CC, Shaw RP. The impact of health insurance in low-and middle-income countries. Brookings Institution Press, 2011.

9 Palmer N, Mueller DH, Gilson L, Mills A, Haines A. Health financing to promote access in low income settings-how much do we know? Lancet 2004;364:1365-70.

10 Ekman B. Community-based health insurance in low-income countries: a systematic review of the evidence. Health Policy Plan 2004;19-249-70.

11 Moreno-Serra R, Smith PC. Does progress towards universal health coverage improve population health? Lancet 2012;380:917-23.

12 Camacho A, Conover E. Effects of subsidized health insurance on newborn health in a developing country. Econ Dev Cultural Change 2013;61:633-58.

13 Sommers BD, Long SK, Baicker K. Changes in mortality after Massachusetts health care reform: a quasi-experimental study. Ann Intern Med 2014:160:585-93.

14 Gruber J, Hendren N, Townsend R. Demand and reimbursement effects of healthcare reform: health care utilization and infant mortality in Thailand. National Bureau of Economic Research, 2012.

15 Bernal MP, Azuara MO, Conti G, Luengas MP. El efecto del Seguro Popular en la salud infantil. Centro de Investigación y Docencia Económicas AC, 2010.

16 King G, Gakidou E, Imai K, Lakin J, Moore RT, Nall C, et al. Public policy for the poor? A randomised assessment of the Mexican universal health insurance programme. Lancet 2009;373:1447-54

17 Gakidou E, Lozano R, González-Pier E, Abbott-Klafter J, Barofsky JT, Bryson-Cahn C, et al. Evaluating the impact of the 2001-2006 Mexican Health Reform: an interim report card. Lancet 2006:368:1920-35.

18 Sosa-Rubi SG, Galarraga O, Harris JE. Heterogeneous impact of the "Seguro Popular" program on the utilization of obstetrical services in Mexico, 2001-2006: a multinomial probit model with a discrete endogenous variable. $J$ Health Econ 2009;28:20-34.
19 Sosa-Rubí SG, Galárraga O, López-Ridaura R. Diabetes treatment and control: the effect of public health insurance for the poor in Mexico. Bull World Health Organ 2009;87:512-9.

20 Powell-Jackson T, Hanson K, Whitty CJ, Ansah EK. Who benefits from free healthcare? Evidence from a randomized experiment in Ghana. $J$ Development Economics 2013;107:305-19.

21 Ansah EK, Narh-Bana S, Asiamah S, Dzordzordzi V, Biantey K, Dickson K, et al. Effect of removing direct payment for health care on utilisation and health outcomes in Ghanaian children: a randomised controlled trial. PLoS Med 2009;6:e1000007.

22 Fink G, Robyn PJ, Sié A, Sauerborn R. Does health insurance improve health? Evidence from a randomized community-based insurance rollout in rural Burkina Faso. $J$ Health Econ 2013;32:1043-56.

23 Dow WH, Schmeer KK. Health insurance and child mortality in Costa Rica. Soc Sci Med 2003;57:975-86

24 Wagstaff A, Lindelow M, Jun G, Ling X, Juncheng Q. Extending health insurance to the rural population: an impact evaluation of China's new cooperative medical scheme. $J$ Health Econ 2009;28:1-19.

25 Lin W, Liu GG, Chen G. The urban resident basic medical insurance: a landmark reform towards universal coverage in China. Health Econ 2009;18(S2):S83-96.

26 Office of the Registrar General and Census Commissioner, India. Summary-report on causes of death: 2001-03 in India. Government of India. 2011. http://censusindia.gov.in/

27 Wang H, Yip W, Zhang L, Hsiao WC. The impact of rural mutual health care on health status: evaluation of a social experiment in rural China. Health Econ 2009;18(S2):S65-82.

28 High Level Expert Group Report on Universal Health Coverage for India. Planning Commission of India, 2011. www.uhc-india.org/.

29 Rani M, Bonu S, Jha P, Nguyen S, Jamjoum L. Tobacco use in India: prevalence and predictors of smoking and chewing in a national cross sectional household survey. Tob Control 2003;12:e4-e.

\section{Accepted: 24 July 2014}

\section{Cite this as: BMJ 2014;349:g5114}

This is an Open Access article distributed in accordance with the Creative Commons Attribution Non Commercial (CC BY-NC 3.0) license, which permits others to distribute, remix, adapt, build upon this work non-commercially, and license their derivative works on different terms, provided the original work is properly cited and the use is non-commercial. See: http://creativecommons.org/licenses/by-nc/3.0/. 


\section{Tables}

Table 1| Village level characteristics used for propensity score matching according to eligibility for government insurance program covering tertiary care for people below poverty line-Vajpayee Arogyashree scheme (VAS)

Demographics* VAS eligible (300 villages) VAS ineligible (272 villages) P value†

\begin{tabular}{llll} 
Age $<6$ & $14.4 \%$ & $14.1 \%$ & 0.14 \\
\hline$\%$ Female aged $<6$ & $48.5 \%$ & $48.6 \%$ & 0.65 \\
\hline Scheduled caste $\neq$ & $21.0 \%$ & $21.3 \%$ & 0.94 \\
\hline Scheduled tribeł & $14.9 \%$ & $12.8 \%$ & 0.15 \\
\hline Female literacy & $43.1 \%$ & $44.3 \%$ & 0.29 \\
\hline Population employed & $50.6 \%$ & $49.8 \%$ & 0.19
\end{tabular}

*Data from 2001 census.

†Estimated from $t$ tests.

‡Historically disadvantaged communities. 
Table 2| Village level development and health related characteristics according to eligibility for government insurance program covering tertiary care for people below poverty line-Vajpayee Arogyashree scheme (VAS)

\begin{tabular}{lccc} 
& VAS eligible (300 villages) & VAS ineligible (272 villages) & P value* $^{*}$ \\
\hline Development indicators & & $48.2 \%$ & 0.71 \\
\hline Piped water & $49.7 \%$ & $92.6 \%$ & 0.20 \\
\hline Electricity in most households & $95.1 \%$ & $34.6 \%$ & 0.01 \\
\hline Bank in village & $25.0 \%$ & 12.2 & 0.14 \\
\hline Distance to nearest town $(\mathrm{km})$ & 13.3 & $87.6 \%$ & 0.41 \\
\hline All weather road in village & $85.3 \%$ & $19.8 \%$ & 0.61 \\
\hline Primary health center in village & $21.5 \%$ & $38.5 \%$ & 0.18 \\
\hline Private clinic in village & $44.1 \%$ & & 0.15 \\
\hline Health behaviors ${ }^{\star}$ & & $53.8 \%$ & 0.91 \\
\hline Most men heavy drinkers & $59.7 \%$ & $67.0 \%$ & \\
\hline Most use tobacco & $67.3 \%$ & & \\
\hline
\end{tabular}

*Estimated from $t$ tests.

†Data from Asha survey (572 villages). Tobacco use measures are consistent with prior work assessing use of tobacco in India. 
Table 3| Out-of-pocket expenditures (in Indian rupees*) for conditions covered by government insurance program covering tertiary care for people below poverty line-Vajpayee Arogyashree scheme (VAS)

\begin{tabular}{|c|c|c|c|c|}
\hline & \multicolumn{2}{|c|}{ Mean out-of-pocket expenditures* } & \multicolumn{2}{|c|}{$\%$ Difference in expenditure } \\
\hline & VAS area & Non-VAS area & Unadjusted & Adjusted $†$ \\
\hline All facilities ( $n=986)$ & 32256 & 49238 & $-34 \%(P<0.001)$ & $-39 \%(P<0.001)$ \\
\hline $\begin{array}{l}\text { Tertiary care facilities (TCFs) } \\
(\mathrm{n}=199)\end{array}$ & 26725 & 62966 & $-58 \%(P<0.001)$ & $-60 \%(P<0.001)$ \\
\hline $\begin{array}{l}\text { TCFs excluding emergency } \\
\text { department admissions and } \\
\text { stays of } \leq 4 \text { days }(n=139)\end{array}$ & 24725 & 73134 & $-66 \%(P<0.001)$ & $-69 \%(P<0.001)$ \\
\hline
\end{tabular}

\section{*1000 rupees $=£ 10(€ 12, \$ 16)$.}

†Adjusted for illness composition (burns, neonatal conditions, cancers, cardiac conditions, neurological diseases, renal conditions, and poly trauma) using ordinary least squares with standard errors clustered at village level. 
Table 4| Utilization of tertiary care covered by government insurance program covering tertiary care for people below poverty line-Vajpayee Arogyashree scheme (VAS)

No $(\%)$ in VAS area $(n=22 \quad$ No $(\%)$ in non-VAS area

796) ( $n=21767)$

\% Difference Unadjusted (P value) $\quad$ Adjusted $^{*}(P$ value)

Households using tertiary care facility for potentially covered conditions

\begin{tabular}{|c|c|c|c|c|}
\hline All facilities & $487(2.1)$ & $486(2.2)$ & $-4.3 \%(0.52)$ & $-5.4 \%(0.64)$ \\
\hline All tertiary care facilities (TCFs) & $107(0.5)$ & $91(0.4)$ & $12.3 \%(0.46)$ & $19.9 \%(0.26)$ \\
\hline $\begin{array}{l}\text { Excluding emergency department } \\
\text { admissions and stays of } 4 \leq \text { days }\end{array}$ & $77(0.3)$ & $51(0.2)$ & $44.2 \%(0.06)$ & $42.7 \%(0.08)$ \\
\hline \multicolumn{5}{|c|}{ Households reporting forgone need for care for VAS condition } \\
\hline Reported forgone need & $52(0.2)$ & $77(0.4)$ & $-35.5 \%(0.07)$ & $-33.4 \%(0.09)$ \\
\hline
\end{tabular}

*Adjusted for village level characteristics using ordinary least squares, including whether most households have piped water, whether there is all weather road in village, distance to nearest town, whether there is clinic or hospital in village, whether there is bank in village, average household income, proportion of people who use tobacco, proportion of people who drink alcohol, and average self reported health score. Standard errors clustered at village level. 


\section{Figures}

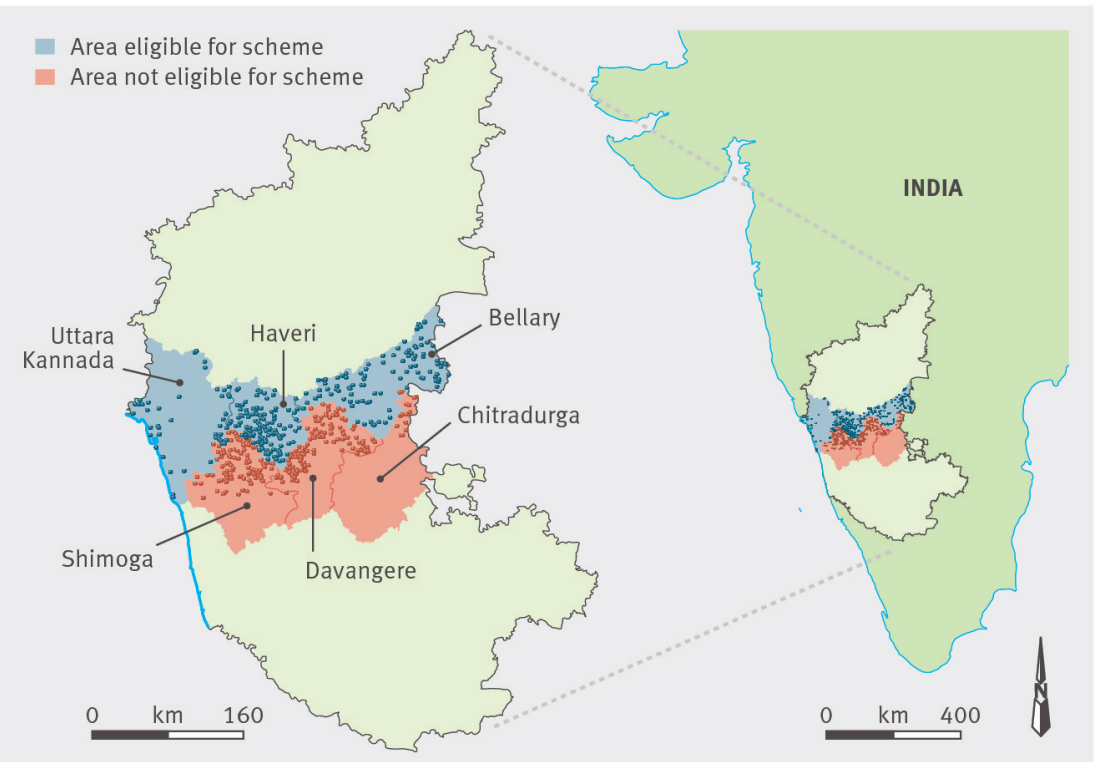

Fig 1 Study region in investigation of government health insurance for people below poverty line. Dots represent sampled villages. Map on left is state of Karnataka; map on right is zoomed out to show southeastern part of India

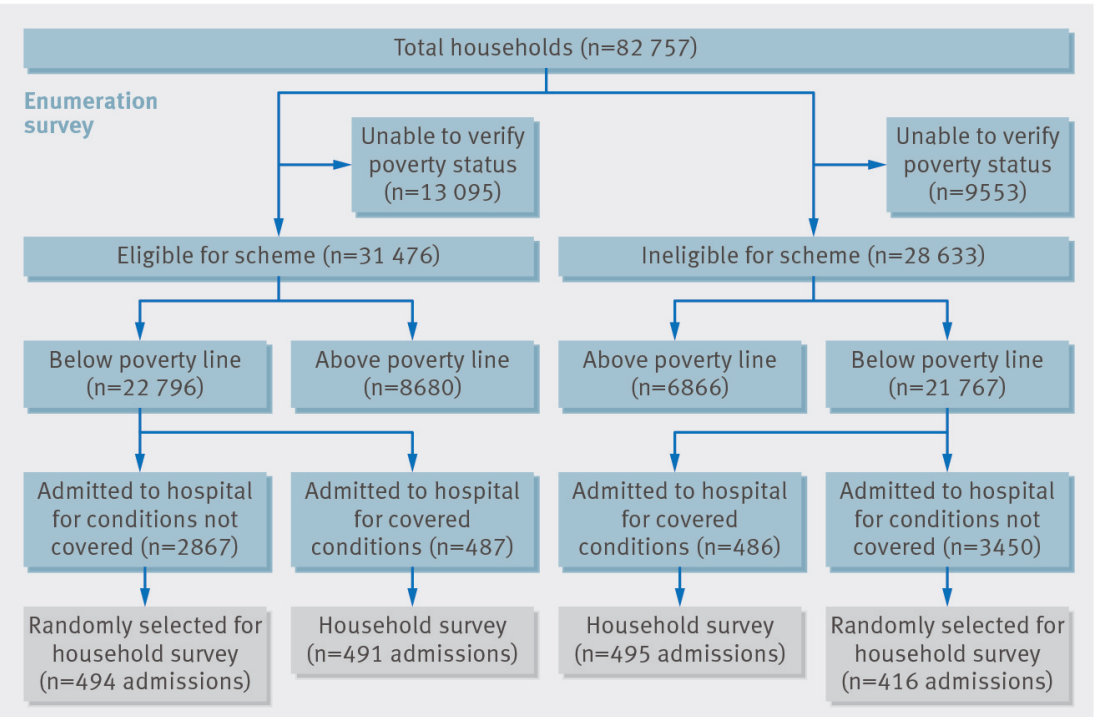

Fig 2 Flow chart of participants in study of government health insurance for people below poverty line in India 


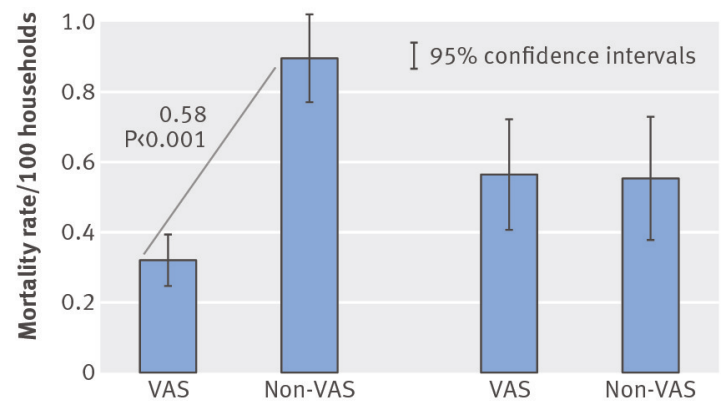

Below poverty line

Above poverty line

Fig 3 Proportion of households that reported death during previous year from conditions covered by scheme according to geographic elegibilty. Households above poverty line are not eligible for scheme. VAS=north of border and eligible for scheme. Non-VAS=south of border and not eligible for scheme

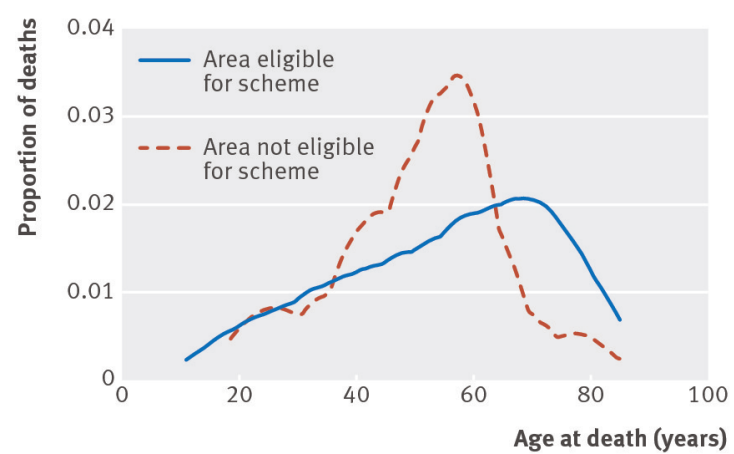

Fig 4 Mortality by age for conditions covered by scheme 